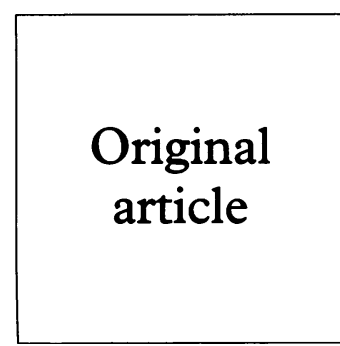

Original
article

\author{
A Nardone, D E Mercey, A M Johnson
}

\section{Surveillance of sexual behaviour among homosexual men in a central London health authority}

Objective: To establish a surveillance mechanism of high risk sexual behaviour among homosexual and bisexual men living, socialising and using services in a central London health authority.

Design: Baseline survey for a system of repeatable behavioural surveillance using a self-completed questionnaire delivered by healthcare providers.

Setting: Genitourinary medicine clinics, gay bars, clubs, community groups and a cruising ground in the defined geographical area of a central London health authority.

Participants: Five hundred and fifty three homosexual and bisexual men.

Main outcome measures: Self-reported behaviours including unprotected anal intercourse (UAI), HIV status of unprotected anal intercourse partners, uptake of HIV testing and use of condoms at first time of anal intercourse.

Results: Five hundred and sixty questionnaires were returned (response rate 76\%) from 553 men. A third (35\%) of men surveyed had had UAI in the previous year. Nearly a fifth (19\%) of the sample had had UAI with one or more partners of a discordant or unknown HIV status. A $\infty$ total of $343(63 \%)$ men had had an HIV test. The proportion of men using condoms on the 9 occasion of first anal intercourse has risen from $6 \%$ before 1980 to $88 \%$ after 1993.

Conclusions: We have demonstrated that a surveillance programme to monitor high risk sexual behaviour among homosexual men can be easily established. The results can be employed to assess progress towards risk reduction targets and also inform future policy development. Our baseline data demonstrate that a large proportion of homosexual men are continuing to engage in high risk sexual behaviour, although there is some evidence of improvement in condom use at first anal intercourse over time. There is a need for continuing health promotion with evaluation among homosexual men.

(Genitourin Med 1997;73:198-202)

Keywords: surveillance; homosexual men; risk factors

Department of Sexually Transmitted Diseases, Division of Pathology and Infectious Disease, University College London Medical School and Camden \& Islington Community Health Services NHS Trust, Mortimer Market Centre, off Capper Street, London WC1E 6AU, UK A Nardone

D E Mercey

A M Johnson

Correspondence to: Dr A Nardone.

Accepted for publication 4 December 1996

\section{Introduction}

Homosexual men have been most severely affected by the HIV/AIDS epidemic in the United Kingdom. Two thirds of all AIDS cases reported to the Communicable Disease Surveillance Centre (CDSC) between 1993 and June 1995 were thought to have been acquired through sex between men. ${ }^{1}$ Furthermore, it has been demonstrated that the prevalence of HIV is higher among homosexual men living in and around London than elsewhere in the United Kingdom. ${ }^{23}$

In the mid to late $1980 \mathrm{~s}$, in response to the HIV/AIDS epidemic, there appeared to be a reduction in the level of high risk sexual behaviour and in the transmission of HIV among homosexual men. ${ }^{45}$ However, in the early 1990s, data from behavioural surveys ${ }^{6}$ and notifications of acute STDs $^{7}$ indicated a possible reversal in these trends. ${ }^{8}$ Evidence for the continued transmission of HIV infection has been obtained from four London genitourinary medicine clinics where the incidence of HIV between January 1988 and April 1994 has remained unchanged (at approximately $4 \%$ per annum) among homosexual/bisexual men having repeat voluntary named HIV testing. ${ }^{9}$
The continuing transmission of HIV, despite health promotion work, has raised the need for an active behavioural surveillance programme. ${ }^{8}$ We report here on the methodology and baseline data of such a system which has been recently established within a central London health authority. This study has anticipated recent recommendations both from government health departments ${ }^{10}$ and scientific advisory bodies. ${ }^{8}$ A questionnaire was developed to monitor high risk sexual behaviour among homosexual men in which measures that are repeatable and sensitive to changes over time were included. A representative sample of "gay" venues in the area was selected in which the questionnaire was distributed by health workers. The results obtained from the survey are used to inform local health purchasers and providers with the targeting and evaluation of health promotion within the homosexual population.

\section{Methods}

Homosexual men who either lived, used services, worked or socialised in the defined geographical area of the health authority were 
eligible for inclusion in the survey. A sampling frame was constructed by listing all venues known to be used particularly by homosexual men in the health authority which included genitourinary medicine (GUM) clinics, bars, clubs, community youth groups and public sex grounds". Sites in which the questionnaires were to be distributed were selected to be representative on three counts: by geography, by the type of venue (for example bar or club) and by the presence of health promotion initiatives. This sample included two of four GUM clinics, five of 11 bars, two of four clubs, two of six community youth groups and one of three PSEs.

The selected venues were visited by health promotion workers as part of their routine work between July and August 1995. All men present in the above locations (except in the PSE) were offered a brief, self-completed and anonymous questionnaire. The questionnaire required less than five minutes to answer and consisted of 15 questions asking demographic details, use of sexual health services and sexual behaviour. They were returned to the health worker once completed. In the PSE, the questionnaires were included in a safer sex pack distributed from a stall and completed forms were returned using reply paid envelopes.

High risk sexual behaviour among homosexual men surveyed was assessed using the following four measures which are both repeatable and sensitive to changes over time:

(1) The number of men with whom the individual had had unprotected anal intercourse (UAI) in the previous year. Men were asked to divide their partners into those with whom they had had UAI only once (casual) or more often (regular).

(2) HIV status of UAI partners: whether the partners with whom an individual has had UAI were of the same, discordant or unknown HIV status.

(3) Time of last HIV test.

(4) The use of condoms at the time of first anal intercourse by year that the event occurred.

Data were entered into EPI INFO and analysed using both EPI INFO and SPSS software programs. Bivariate analyses were undertaken using $\chi^{2}$ tests for categorical variables and either Student's $t$ tests or Mann-Whitney U tests for continuous variables. The multivariate analysis employed was an unconditional logistic regression performed using SPSS software in which continuous variables were grouped into categories reflecting quartile ranges. environments (PSE) such as "cruising

\section{Results}

The overall response rate of the survey was $75 \%$ and ranged from $97 \%$ (community groups) to $11 \%$ (PSE). A total of 560 forms were returned from the selected locations within the health authority (see table 1).

Two questions (regarding the last time of unprotected anal intercourse) were posed to check the internal consistency of responses. The vast majority of responders $(87 \%)$ gave concordant responses to the two questions, indicating substantial consistency among responses. Subjects were asked whether they had already completed the questionnaire. Of the 560 questionnaires returned, seven individuals had already completed the questionnaire and so were excluded from further analysis.

Of the 550 responses which included complete data regarding age, 121 men $(22 \%)$ were under 24 years old and the largest age group was between 25 and 29 (33\%). Three men did not state their age. The median age of responders was 29 years old (range 15-70). The sample was predominately white $(91 \%)$, employed (75\%) and living in London (88\%).

All subjects recruited were homosexual $(93 \%)$ or bisexual $(7 \%)$. Thirty two $(6 \%)$ men surveyed had never had anal intercourse with a man and a further $13(3 \%)$ stated that they had not had sex with a man in the past year.

\section{Unprotected anal intercourse}

Of the 499 men who supplied the relevant data, $323(65 \%)$ had not engaged in UAI in the previous year (table 2). Of the $176(35 \%)$ men who had had UAI, 116 had had only one partner (66\%), $49(28 \%)$ had had between two and four partners and $11(6 \%)$ had had five or more partners (table 2). There was no association between having had UAI with one or more men in the past year and any of the variables collected which included: age, ethnicity, area of residence, employment status, site of recruitment, having had an HIV test, attendance at a GUM service in the past year, number of sexual partners in the past year and number of years since first anal intercourse.

Data regarding both the HIV status (see below) and the nature of the relationship (casual versus regular) of UAI partners were collected. In order to avoid possible misinterpretation, casual partners were defined in the questionnaire as men with whom the individual had had UAI once only. One hundred and sixty four men (93\% of those having UAI) had provided data about the type of relationship they had with their UAI partners. Seventy men had had UAI in the past year with one or more

Table 2 The proportion of men who had engaged in unprotected anal intercourse (UAI) in the previous year and number of such partners $(n=499)$

\begin{tabular}{llll}
\hline Site of recruitment & $\begin{array}{l}\text { No of forms } \\
\text { distributed }\end{array}$ & $\begin{array}{l}\text { No of forms } \\
\text { returned }(\%)\end{array}$ & $\begin{array}{l}\text { Response } \\
\text { rate (\%) }\end{array}$ \\
\hline GUM clinic & 180 & $135(24)$ & 75 \\
Bars/pubs & 304 & $252(45)$ & 83 \\
Clubs & 151 & $137(25)$ & 91 \\
Other sites & 104 & $36(6)$ & 35 \\
$\quad$ community groups and PSE) & 104 & $560(100)$ & 76 \\
Total & 739 & & \\
\hline
\end{tabular}

\begin{tabular}{lc} 
and number of such partners $(n=499)$ & \\
\hline Number of UAI partners in the past year & Number (\%) \\
\hline 0 & $323(65)$ \\
1 & $116(23)$ \\
$2-4$ & $49(10)$ \\
5 or more & $11(2)$ \\
Total & $499(100)$ \\
\hline
\end{tabular}


Table 3 The proportion of men who had engaged in unprotected anal intercourse (UAI) with partners once only (casual partners) in the previous year and number of such partners $(n=487)$

\begin{tabular}{lc}
\hline Type of UAI partner in the past year & Number (\%) \\
\hline No UAI partners & $323(65)$ \\
Had UAI but not with & $94(19)$ \\
$\quad$ casual partners & $70(14)$ \\
$\quad$ casual partners & $487(100)$ \\
\hline
\end{tabular}

Table 4 The proportion of men who had engaged in unprotected anal intercourse with partners of unknown or discordant HIV status in the previous year $(n=477)$

\begin{tabular}{lc}
\hline HIV status of UAI partners in the past year & Number (\%) \\
\hline No UAI partners & $323(68)$ \\
UAI with partners of concordant & $62(13)$ \\
HIV status & $92(19)$ \\
UAI with partners of discordant or & $477(100)$ \\
unknown HIV status & \\
Total &
\end{tabular}

casual partners, which represents $43 \%$ of all men who had had UAI or $14 \%$ of all men surveyed (table 3 ).

\section{HIV status of UAI partners}

One hundred and fifty four men $(88 \%$ of men having UAI) provided data about the HIV status of their UAI partners. Ninety two $(60 \%)$ men did not know whether all their UAI partners were of the same HIV status as themselves. This represents $19 \%$ of all men surveyed (table 4).

There was no association between known HIV seroconcordance of UAI partner and any of the demographic and service using variables collected. However, men who, in the past year, had engaged in UAI with partners of unknown or discordant HIV status were more likely to have had UAI with a higher number of partners and with casual rather than regular partners. UAI with casual partners was the only independent indicator of UAI with partners of discordant or unknown HIV status.

Previous HIV test

Of the 546 men who responded to this question, $203(37 \%)$ had never had an HIV test (table 5). Five variables significantly associ-? ated with HIV testing were included in a mul- $\overrightarrow{\vec{D}}$ tiple logistic regression model: ethnic group, $\frac{\vec{\sigma}}{0}$ age, attendance at GUM service in past year, number of male sexual partners in past year $\overline{\bar{c}}$ and years since first anal intercourse. $\stackrel{0}{\circ}$ However, of these only two variables were sig- क nificantly associated with having had an HIV test (table 5): attendance at a GUM service (OR, 1.56; 95\% CI 1.28-1.96) and increasing $\vec{\omega}$ years since first anal intercourse (OR, 2.07; $95 \%$ CI $1 \cdot 36-3 \cdot 15)$.

\section{Condom use at time of first anal intercourse}

The proportion of men using condoms on the $\infty$ occasion of first anal intercourse has risen 9 from $6 \%$ before 1980 to $90 \%$ after 1993 (fig).

\section{Discussion}

The primary aim of this study was to establish. a system of active surveillance which can be used to monitor changes in high risk sexual behaviour, over time, among homo/bisexual men living, working, socialising and/or using services in a central London health authority. We report here on the baseline survey which will supply local public health specialists with

Table 5 Unadjusted and adjusted odds ratio of ever having had an HIV test. A multivariate logistic regression was performed in which all variables that were significantly associated with ever having had an HIV test were incorporated into the model

\begin{tabular}{|c|c|c|c|c|c|}
\hline & & $\begin{array}{l}\text { Ever } \\
\text { tested } \\
\text { for HIV }\end{array}$ & $\begin{array}{l}\text { Never } \\
\text { tested } \\
\text { for HIV }\end{array}$ & $\begin{array}{l}\text { Unadjusted } \\
\text { odds ratio } \\
(95 \% \text { CI) }\end{array}$ & $\begin{array}{l}\text { Adjusted } \\
\text { odds ratio } \\
\text { (95\% CI) }\end{array}$ \\
\hline \multicolumn{2}{|l|}{ All men surveyed } & 343 & 203 & - & - \\
\hline \multirow{2}{*}{$\begin{array}{l}\text { Attending a } \\
\text { GUM clinic } \\
\text { in past year }\end{array}$} & Yes & 223 & 79 & \multirow[t]{2}{*}{$\begin{array}{c}2 \cdot 89^{\star} \\
(1 \cdot 99-4 \cdot 21)\end{array}$} & \multirow{2}{*}{$\begin{array}{c}1 \cdot 56^{\star} \\
(1 \cdot 28-1.96)\end{array}$} \\
\hline & No & 120 & 123 & & \\
\hline \multirow{4}{*}{$\begin{array}{l}\text { Years since first } \\
\text { anal intercourse }\end{array}$} & $0-4$ & 50 & 66 & $1 \cdot 00$ & $1 \cdot 00$ \\
\hline & $5-9$ & 82 & 57 & \multirow{4}{*}{$\begin{array}{c}1 \cdot 90^{\star} \\
(1 \cdot 12-3 \cdot 23) \\
5 \cdot 28^{\star} \\
(2 \cdot 85-9 \cdot 84) \\
4 \cdot 08^{\star} \\
(2 \cdot 29-7 \cdot 30) \\
1 \cdot 00\end{array}$} & \multirow{4}{*}{$\begin{array}{c}2 \cdot 54^{\star} \\
(1 \cdot 36-3 \cdot 15) \\
1 \cdot 38^{\star} \\
(1 \cdot 09-2 \cdot 27) \\
0 \cdot 42^{\star} \\
(0 \cdot 35-0 \cdot 81) \\
1 \cdot 00\end{array}$} \\
\hline & $10-14$ & 96 & 24 & & \\
\hline & $\geqslant 15$ & 99 & 32 & & \\
\hline \multirow[t]{4}{*}{ Age group } & $\leqslant 25$ & 50 & 68 & & \\
\hline & $26-29$ & 92 & 53 & \multirow{4}{*}{$\begin{array}{c}2 \cdot 36^{\star} \\
(1 \cdot 39-4 \cdot 01) \\
3 \cdot 67^{\star} \\
(2 \cdot 13-6 \cdot 36) \\
2 \cdot 95^{\star} \\
(2 \cdot 29-7 \cdot 30) \\
1 \cdot 00\end{array}$} & \multirow{4}{*}{$\begin{array}{c}1.52 \\
(0.82-2 \cdot 80) \\
1.76 \\
(0.89-3.47) \\
0.87 \\
(0.39-1.91) \\
1.00\end{array}$} \\
\hline & $30-33$ & 108 & 40 & & \\
\hline & $\geqslant 34$ & 91 & 42 & & \\
\hline \multirow{4}{*}{$\begin{array}{l}\text { No of male } \\
\text { sexual partners } \\
\text { in past year }\end{array}$} & $\leqslant 3$ & 66 & 68 & & \\
\hline & $4-10$ & 80 & 44 & \multirow{5}{*}{$\begin{array}{c}1 \cdot 87^{\star} \\
(1 \cdot 10-3 \cdot 19) \\
1 \cdot 75^{\star} \\
(1 \cdot 04-2 \cdot 97) \\
2 \cdot 97^{\star} \\
(1 \cdot 72-5 \cdot 15) \\
1 \cdot 94 \dagger \\
(1 \cdot 03-3 \cdot 65)\end{array}$} & \multirow{5}{*}{$\begin{array}{c}1.61 \\
(0.90-2 \cdot 88) \\
1.14 \\
(0.64-2.04) \\
1.92 \\
(1.05-3.50) \\
1.85 \\
(0.91-3.85)\end{array}$} \\
\hline & $11-25$ & 80 & 47 & & \\
\hline & $\geqslant 26$ & 98 & 34 & & \\
\hline \multirow[t]{2}{*}{$\begin{array}{l}\text { Ethnic } \\
\text { group }\end{array}$} & White & 317 & 178 & & \\
\hline & $\begin{array}{l}\text { Non- } \\
\text { white }\end{array}$ & 23 & 25 & & \\
\hline
\end{tabular}




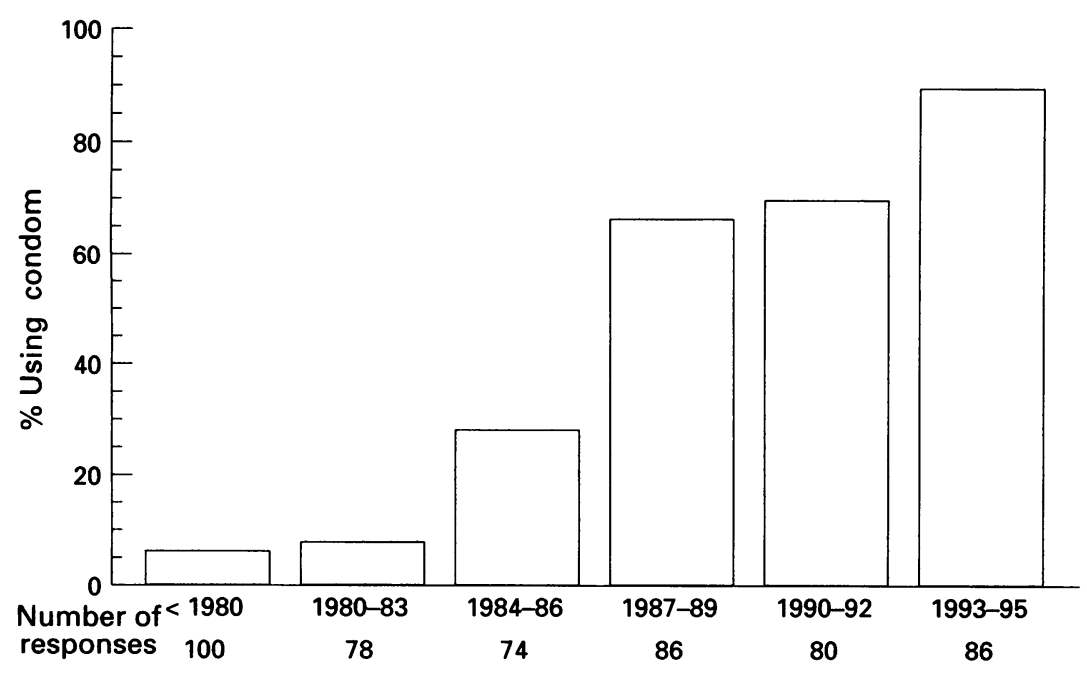

Year of first anal intercourse

Demonstrates, by year of first anal intercourse, the proportion of men who used a condom on that occasion. behaviour in homosexual men. ${ }^{13} 14$ These studies have used an external check (such as second interview ${ }^{13}$ or interviews with sexual partners ${ }^{14}$ ) to ascertain the validity of survey responses. However, an alternative approach to ensuring the validity of responses is to employ internal consistency checks within the questionnaire. ${ }^{15}$ This methodology emerged as the most appropriate for this survey and provided evidence for substantial consistency among the responses.

Data from this survey have demonstrated that the majority of homosexual men have not, in the past year, engaged in high risk sexual behaviour (two thirds not having had UAI in the previous year). However, a significant minority are still engaging in high risk sexual behaviour. A third of men (34\%) surveyed had had UAI with one or more male partners in the previous year, an observation consistent with other studies. ${ }^{16}$ However, the use of UAI as the only index of unsafe sexual behaviour has been criticised for not acknowledging the full range of strategies utilised by homosexual men to protect themselves from HIV infection. ${ }^{17}$

Of the sample of men surveyed, $19 \%$ had within the past year engaged in sexual behaviour that carried the highest risk of HIV transmission, that is UAI with partners of unknown or discordant HIV status. If this observation is combined with that of high prevalence of HIV among homosexual men noted in many different surveys, ${ }^{318}$ then the conditions are suitable for the continued transmission of HIV. It has been reported that in London, between 1988 and 1994, the incidence of HIV among homosexual men having a repeat voluntary HIV test has remained unchanged at 3.8 per 100 person years. ${ }^{9}$ These observations confirm the need for continued health promotion among homosexual men rather than the relaxing of efforts feared by some commentators. ${ }^{19}$

Many studies have demonstrated that homosexual men are well informed in the modes and prevention of transmission of HIV infection. ${ }^{20}$ None the less, this survey has found, as have others, ${ }^{6} 16$ that significant proportions of men continue to engage in high risk behaviour. Thus, health promotion must include innovative safer sex strategies for homosexual men such as ensuring that all UAI partners are of the same HIV status. However, although this approach may reduce the chances of HIV transmission, it is often a difficult strategy to employ and less suitable for casual partners. ${ }^{17}$

Testing for HIV is a component of a number of safer sex strategies including that of negotiated safety. ${ }^{17}$ In agreement with other studies, ${ }^{616}$ the majority of homosexual men surveyed (63\%) have had an HIV test sometime in the past. However, having had an HIV test did not predict the sexual behaviour of individuals. The efficacy of including HIV testing as a part of an HIV prevention strategy is yet to be properly evaluated. ${ }^{21}$

A number of studies in the UK and USA have suggested that young homosexual men have higher levels of risk behaviour than their 
older counterparts. ${ }^{722}$ In contrast, a survey of homosexual men attending a Gay Pride event in London did not demonstrate any relation between age and sexual behaviour. ${ }^{16}$ This observation is consistent with our data which demonstrate a lack of an association between age and any of the indices of high risk sexual behaviour used in this survey. However, there may be a possible selection bias in that older homosexual men who continue to go to commercial venues may also be those that are more sexually active.

Since the early 1980s, there has been an increase in the proportion of homosexual men using condoms on the occasion of first anal intercourse, also noted by other surveys. ${ }^{16}$ This demonstrates that it is possible to achieve major changes in sexual behaviour. The trend in condom use may represent the establishment of new community norms which have been proposed as the most effective strategy of preventive medicine. ${ }^{23}$

The study has demonstrated that a surveillance programme can be effectively and efficiently established. We intend to repeat this work in future years to obtain trends in behaviour which will be used to guide local health promotion strategy. The majority of homosexual men in a central London health authority, in the past year, have had only safer sex. None the less, a large and significant minority have, in the same period of time, engaged in some form of high risk sexual behaviour. The combination of both HIV infection and high risk behaviour among homosexual men indicates the likelihood of continued transmission of HIV. Thus, there is a need for continued and innovative approaches to health promotion among homosexual men.

We gratefully acknowledge the financial support provided by Camden \& Islington Health Authority and Camden \& Islington Community Health Services NHS Trust.

We thank Martin Calleja, Colin Dixon, Andrew Beathan, Fraser Searle, Martin Dockerell and Andrew Billington for distribution of questionnaires. Also many thanks to Andrew Copas for his statistical advice and Judith Stephenson for her comments.

1 PHLS AIDS Centre-Communicable Disease Surveillance, and Scottish Centre for Infection \& Environmental Health. Unpublished quarterly surveillance Tables No 28, June 1995, Table 10 .

2 Waight PA, Rush AM, Miller E. Surveillance of HIV infection by voluntary testing in England. Communicable Disease Report 1992;2:R85-R90.
3 Report from the Unlinked Anonymous HIV Surveys Steering Group. Unlinked Anonymous HIV Prevalence Monitoring Programme: England \& Wales. Data to the end of 1994. London: Department of Health 1995

4 Carne CA, Weller IVD, Johnson, AM, Loveday C, Pearce F Hawkins A, et al. Prevalence of antibodies to human immuno-deficiency virus, gonorrhoea rates, and changed sexual behaviour in homosexual men in London. Lancet 1987;i:656-8.

5 Johnson AM, Gill ON. Evidence for recent changes in sexual behaviour in homosexual men in England \& Wales. Philos Trans $R$ Soc Lond (Biol) 1986;325:153-61.

6 Dawson JM, Fitzpatrick RM, Reeves G, Boulton M, McLean J, Hart GJ, et al. Awareness of sexual partners' HIV status as an influence upon high-risk sexual behaviour among gay men. AIDS 1994;8:837-41.

7 Evans BG, Catchpole MA, Heponstall J, Mortimer JY, McCarrigle CA, Nicoll AG, et al. Sexually transmitted diseases and HIV-1 infection among homosexual men in $\overline{\bar{F}}$ England \& Wales. BMf 1993;306:426-8.

8 Report of a working group (Chairman: Professor NE Day) convened by the Director of the Public Health Laboratory Service on behalf of Chief Medical Officers. The incidence and prevalence of AIDS and prevalence of other severe HIV disease in England and Wales for 1995 त to 1999: projections using data to the end of 1994 .

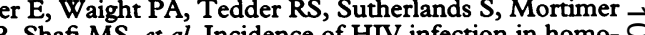
Pexul $m$ in in

10 Department of Health. HIV and AIDS health promotion: an $\vec{\omega}$ evolving strategy. London: DoH 1995.

11 Steiner S, Lemke AL, Roffman RA. Risk behaviour for $\mathscr{S}$ HIV transmission among gay men surveyed in Seattle Bars. Public Health Reports 1994;109:563-6.

12 Perry MJ, Solomon LJ, Winett RA, Kelly JA, Raffaman c RA, Desiderato LL, et al. High risk behaviour and alcohol consumption among bar-going gay men. AIDS 1994;8:1321-4.

13 Saltzman S, Stoddard A, McCusker J, Moon MW, Mayer 음 $\mathrm{KH}$. Reliability of self-reported sexual behaviour risk factors for HIV infection in homosexual men. Public Health tors for HIV infection in

14 Coates R, Calzavra L, Sosklone C, Read SE, Fauming MM, Shepherd FA, et al. Validity of sexual histories in a prospective study of male sexual contacts of men with AIDS or an AIDS related condition. Am $\mathcal{f}$ Epidemiol 1988;128:719-28.

15 Johnson AM, Wadsworth J, Wellings K, Field J. Sexual Attitudes and Lifestyles. Oxford: Blackwell, 1994.

16 Hickson F, Beardsell S, Broderisk P, Davies P, Keogh P, Reid D, et al. The gay men's sex survey at pride ' $94 . \bar{O}$ Reid D, et al. The gay
Project SIGMA 1994.

17 Kippax S, Crawford J, Davis M, Rodden P, Dowsett G. $\stackrel{\odot}{\mathbb{D}}$ Sustaining safe sex: a longitudinal study of a sample of homosexual men. AIDS 1993;7:257-63.

18 Hart GJ, Dawson J, Fitzpatrick RH, Boulton M, McLean J, Brookes $\mathrm{M}$, et al. Risk behaviour, anti $\mathrm{HIV}$ and anti hepatitis $\mathrm{B}$ core prevalence in clinic and non-clinic sample of gay men in England, 1991-1992. AIDS 1993;7:우․ 863-96.

19 Stall $R$. How to lose the fight against AIDS among gay men. $B M F$ 1994;309:685-6.

20 Hunt AJ, Davies PM, Weatherburn P, Coxon AM, McManus TJ. Changes in sexual behaviour in a large. cohort of homosexual men in England and Wales. BMFO 1994;302:505-6.

21 Beardsell S. Should wider HIV testing be encouraged on the grounds of HIV prevention? AIDS Care 1994;6:5-19.

22 Ekstrand ML, Coates TJ. Maintenance of safe sexual behaviours and predictors of risky sex: the San Francisco음 Men's Health Study. Am f Public Health 1990;80: 973-7.

23 Rose G. The Strategy of Preventative Medicine. Oxford:Oxford University Press, 1992. 